\title{
CUADROS DE HISTORIA: JACINTO CHACÓN BAREY. ARTE Y LITERATURA SIGLO XIX EN CHILE ${ }^{1}$
}

\author{
Pictures of history: Jacinto Chacón Barey. \\ Nineteenth century art and literature in Chile
}

\author{
Alberto Madrid * \\ Pedro Zamorano ** \\ Claudio Cortés ${ }^{* * *}$
}

\section{RESUMEN}

A mediados del siglo XIX se inicia en Chile el proceso de la formalización de las instituciones educativas por parte del Estado. En este contexto se funda la Academia de Pintura en 1849. En su inauguración se leen dos discursos: uno por su Director, Alejandro Cicarelli y a continuación su contestación en verso por Jacinto Chacón. El primero ha sido más citado y estudiado, en tanto el segundo no ha sido lo suficientemente analizado. Interesa el último teniendo como correlato la relación de la literatura y el arte, desde una lectura revisionista y como fuente de documentación para el estudio de las artes visuales chilenas.

Palabras clave: Academia de Pintura, discursos, arte-literatura siglo XIX.

\footnotetext{
*Facultad de Arte, Universidad de Playa Ancha. Valparaíso, Chile. Correo electrónico: amadrid@upla.cl

** Instituto de Estudios Humanísticos "Juan Ignacio Molina", Universidad de Talca. Talca, Chile. Correo electrónico: zamoper@utalca.cl.

*** Facultad de Arquitectura y Urbanismo, Departamento de Diseńo, Universidad de Chile. Santiago, Chile. Correo electrónico: c.cortes@uchilefau.cl

${ }^{1}$ Artículo realizado en el marco del Proyecto $\mathrm{N}^{\circ} 1110647$ del Fondo Nacional de Desarrollo Científico y Tecnológico (FONDECYT), titulado: "Construcción del gusto: la crítica del arte en Chile desde 1849 a 1970". Investigador Responsable: Pedro Zamorano Pérez. Co-Investigador: Alberto Madrid Letelier. Co-Investigador: Claudio Cortés. 


\begin{abstract}
In the mid nineteenth century a process of formalization of the educational institutions was begun by Chilean State. In this context, the Academy of Painting was founded in 1849. At its inauguration, two speeches were read: the first one was read by its director, Alejandro Cicarelli, and the second one was a response in verse to the first one made by Jacinto Chacón. The first one has been more quoted and studied, but the second one has not been sufficiently analyzed. This last speech is the interesting one, considering the relation between literature and art to be a correlate from a revisionist interpretation, and as a source of documentation for the study of Chilean visual arts.
\end{abstract}

Keywords: Academy of painting, speeches, art-literature nineteenth century.

\title{
INTRODUCCIÓN
}

En los discursos del campo artístico chileno del siglo XIX, más específicamente desde mediado de éste, aparecen reiteradamente las expresiones cuadro, pintura, colorido, como figuras retóricas. Se trata de expresiones utilizadas como recurso figural para aludir al contexto, los discursos, imágenes, entre otras significaciones. A modo de ejemplo: Cuadros pintorescos de costumbre alternan con descripciones novedosas de paisajes; ${ }^{2}$ A pesar de su interés por la pintura y las Bellas Artes en general, Grez no es un colorista ni parecen interesarle demasiado los cuadros de género; 3 Yo les tengo algún cariño y no quiero pintarlos con mi brocha, otro día tomaré el pincel y los pondré de azul y plata. ${ }^{4}$ Estas citas, tomadas fragmentadamente, ilustran el uso fronterizo de la expresión cuadro y pintura perteneciente a las Bellas Artes en las construcciones discursivas del período en estudio.

Este trabajo constituye una proposición de análisis sobre las relaciones del arte y la literatura en el campo cultural chileno, teniendo en consideración la semantización del cuadro en analogía con la pintura de género en la cual se cuenta

\footnotetext{
${ }^{2}$ Montes, Hugo y Orlandi, Julio. Historia de la Literatura Chilena. Revisada y puesta al día. 10a edición. Santiago de Chile: Zig-Zag, (1982): 117.

${ }^{3}$ Goic, Cedomil. La novela chilena. Los mitos degradados. 4a edición. Santiago de Chile: Editorial Universitaria, (1976): 190.

${ }^{4}$ Montes, Hugo y Orlandi, Julio, Op. cit., 98.
} 
una historia. También corresponde a una lectura revisionista, en tanto ejercicio de re-visión sobre aspectos no lo suficientemente estudiados en la historiografía del arte nacional.

Un primer momento de acercamiento a la relación del arte y la literatura se puede encontrar en el discurso inaugural de la Academia de Pintura. En las historias del arte chileno se menciona o analiza el discurso pronunciado en la inauguración de la academia por su Director D. Alejandro Cicarelli. Caballero de la Orden Imperial de Cristo. Maestro Honorario de Pintura de la Real Academia de Nápoles, condecorado con la Medalla de oro, título de la publicación de 1849.5 Lo que pasa desapercibido es la segunda parte de la publicación: Seguido de la contestación en verso leída por D. Jacinto Chacón.

La alocución de Jacinto Chacón Barey (1820-1898), a modo de cuadro de historia, da cuenta tanto del clima de época que vive el país, como de la materialización de proyectos institucionales vinculados con el Estado Docente, desarrollados por el gobierno del presidente Manuel Bulnes. La Academia venía a cumplir otro anhelo fundacional. Con anterioridad, en 1841, el Ministro Manuel Montt le encarga a don Andrés Bello la redacción de la Ley Orgánica de la Universidad de Chile, de la que será Rector en 1843, cuando se pone en funcionamiento. Así un acontecimiento más del deseo civilizador y de progreso que vive el país producto de la revolución, como se dice de la Independencia, telón de fondo que enmarca la contestación de Chacón como expresión de poesía cívica.

\section{ALEJANDRO CICARELLI (1808-1870)}

El lector debe imaginar la pompa del momento inaugural en la que participa el presidente de la Nación y la élite ilustrada. Si bien centraremos la atención en la respuesta de Chacón, se debe tener presente la intertextualidad de los discursos con el de Cicarelli, por la continuidad del acto en el sentido de la lectura de éstos, su recepción inmediata y la posterior impresión. Ambos se relacionan en la recitación de imágenes y palabras características de la enciclopedia de lecturas del periodo con las que referencian la elaboración de sus discursos.

${ }^{5}$ Cicarelli, Alejandro. Discurso Pronunciado en la inauguración de la Academia de Pintura. Santiago de Chile: Imprenta Chilena, 1849. 
El cuadro inicial que se resume del discurso de Cicarelli sin seguirlo linealmente respecto del contexto y sus interlocutores, manifiesta por parte del autor:

"Deseo llamar la atención de la estudiosa juventud chilena, para observarle, que la patria le abre una nueva carrera, que le asegura una nueva posición social. La carrera es vasta, i aunque opuesta a la armas, es gloriosa como ella. Si los hijos de la patria derramaron su sangre en los campos de batalla para asegurar su independencia i grandeza, las bellas artes tiene la misión de fecundar esta semilla de virtud i patriotismo, ilustrando por medio del arte las hazañas de esos valientes". ${ }^{6}$

Este enunciado contiene la ideología y la visión del mundo en su momento y la constitución de la Academia; etapa de pacificación que vive el país luego de su Independencia, que se materializa en la institucionalidad cultural que necesita para desarrollarse. Desde un comienzo se ve en la Academia una instancia de formación profesional, a la vez que se asigna la misión de ilustrar a la pintura, característica de la pintura de historia, etapa más avanzada de la formación de los futuros artistas.

Cicarelli es consciente del momento institucional del país y del rol que viene a desempeñar y de ser mediador de saber. Él trae el conocimiento del Viejo Mundo y su experiencia como artista haciendo ver el alcance sobre el lugar de las Bellas Artes en la nueva institucionalidad.

"Pero el arte, señores, no se circunscribe a esta parte científica, sino tiene otro fin. Cuando un nuevo país ya constituido, posee una Universidad de estudios literarios para promover el desenvolvimiento de la inteligencia, como principio de toda concepción, éste principio, esta concepción quedarían sin ninguna realización, aplicación práctica a nuestras necesidades, sino fuesen seguidas de la acción. Esta acción para poderse manifestarse, debe estar consignada en un cuerpo científico i mecánico justamente; esta rueda indispensable entre paciencia i la industria es una Academia de bellas artes".

En el naciente estado de saber del país, el artista ilumina las relaciones de las Bellas Artes con otras áreas del desarrollo de la nación sobre la enseñanza profesional del artista y la formación del gusto.

${ }^{6}$ Cicarelli, Alejandro, Op. cit., 21.

${ }^{7}$ Cicarelli, Alejandro, Op. cit., 20. 
A partir de las asociaciones que propone Cicarelli entre las Bellas Artes y la Literatura se debe tener en consideración el desfase de sus desarrollos. La antecedencia a la apertura a la Academia de Pintura en el campo simbólico del país, es la existencia del Movimiento Literario de 1842 ocupado por la constitución del discurso de lo nacional, el cual está dentro de la institucionalidad universitaria, no aun así las Bellas Artes.

En otra extensión, Cicarelli deja planteado en su discurso un tópico que se va debatir en las décadas siguiente sobres las Bellas Artes entendidas como artes puras y las artes aplicadas a la industria, por lo que a continuación de la Academia se creará la Escuela de Artes y Oficio (1849), como efecto de una política de formación del gusto en el diseño de objetos útiles.

El discurso de Cicarelli representa un cuadro programático sobre su enseñanza y su aporte al desarrollo cultural del país. También se puede considerar como una fuente inicial de documentación y transferencia para la historiografía del arte chileno. Su cuadro resume una interpretación de la historia del arte, en correlato de la visión de Hipólito Taine, aludiendo a sus:

\footnotetext{
"Fases que acompañaron a la historia de las naciones que han existido sobre la superficie de la tierra, fueron siempre las mismas en su nacimiento, desarrollo, decadencia i desaparición, salvo las diferencias anexas a la localidad, clima i temperamento de cada una de ellas". ${ }^{8}$
}

Las categorías utilizadas por Cicarelli serán parte del correlato de su construcción que hace del origen del arte y los efectos de su enseñanza a través de la naciente Academia de Pintura en Chile. En su discurso inaugural, su descripción es evolutiva, parte de la idea de su nacimiento en la arquitectura como la madre de las artes en su manifestación inicial en que el hombre busca el refugio, con posteridad se desarrollará la escultura. La primera, tanto en sus manifestaciones civiles como religiosas (alcance en cuanto a resaltar en el discurso de Cicarelli la presencia de lo religioso, la Católica, quizás consciente del público a quien se dirige). En el horizonte de expectativas de la recepción del período conviven los ideales Conservadores y Liberales, pero ambos bajo la influencia de la Iglesia. Cuando analiza la cultura griega, aplicando las fases mencionadas y su posterior

\footnotetext{
${ }^{8}$ Cicarelli, Alejandro, Op. cit., 5
} 
evolución en la continuidad en Roma, insiste en las condiciones geográficas y climáticas que favorecen lo bello, las que le servirán para comparar "que no era entonces más que una tierra virgen como la América lo era a la época de su descubrimiento". ${ }^{9}$ En otra extensión serán las comparaciones de estos referentes los que inicialmente se utilizarán en el Nuevo Mundo. En la geopolítica de la época, el Viejo Mundo es el canon de los saberes que se explícita "ojala que en nuestro ilustrado siglo los artistas de todas las naciones asociadas consignen este estilo clásico, tomando un canon o modelo, como ejemplo el de Rafael, que puede ser llamado el Zeuxis de nuestra era cristiana”. ${ }^{10}$ Es así como Cicarelli manifestará, de acuerdo a su lectura de la historia y de sus manifestaciones, que el desarrollo de las bellas artes en Chile es posible teniendo en consideración el modelo que viene enunciando. interrumpirá su discurso para señalar: "Cuando examino, señores, el bello cielo de Chile, su posición topográfica, la serenidad de la atmósfera, cuando veo tantas analogías con la Grecia i con la Italia, me inclino a profetizar que en este hermoso país será un día la Aténas de la América del sur”. ${ }^{11}$

Habrá que imaginar la resonancia de las palabras y la gestualidad de los presentes ante la profetización de Cicarelli como consecuencia de la serenidad de la atmósfera que se vive, responde a un momento de pacificación. Cierto que en el período es un momento, ya que después de la inauguración de la Academia se mantendrán los episodios de violencia que son característicos del siglo XIX (Una observación revisionista de las construcciones discursivas de la historiografía del arte chileno muestra que el arte transita en un escenario en que aparentemente no existen conflictos políticos y sociales).

Razones de buena crianza de quien llega hacerse cargo de la enseñanza del arte serán los elogios correspondientes a la ocasión: "Viniendo ahora a nuestro propósito de la apertura de la Academia de pintura, que el sabio Gobierno proporciona a su país..."12

En breve, Cicarelli es consciente de las condiciones de recepción de su discurso -como se ha venido analizando-, tiene manejo de los códigos de época:

${ }^{10}$ Cicarelli, Alejandro, Op. cit., 11.

${ }^{11}$ Cicarelli, Alejandro, Op. cit., 16.

${ }^{12}$ Cicarelli, Alejandro, Op. cit., 22.
} 
del ideario de la Ilustración que experimenta el país sobre el rol de la educación en el progreso, el aporte de las bellas artes, al carácter civilizador de la nación; las condiciones coyunturales el momento de pacificación y de bienestar económico; cierra el discurso destacando el privilegio de dar inicio a las actividades de la Academia de pintura.

\section{JACINTO CHACÓN (1820-1898)}

La alocución poética de Jacinto Chacón, se puede considerar como una apostilla al discurso de Cicarelli, si se tiene en consideración su extensión. La edición de ambas piezas discursivas es de veintisiete páginas, de las cuales cuatro son correspondientes a Chacón.

En relación a lo que se viene señalando sobre artes y literatura en sus invariantes de correspondencia que están presentes en el texto son: el tema, la enseñanza y, ahora en la institucionalidad del campo artístico, es un poeta el que recepciona y acoge el inicio de la Academia representada en su director y su discurso programático. Jacinto Chacón abre su alocución estableciendo la jerarquía de los presentes:

¿Excelencia, Salud! Nobles chilenos
Qué, de virtud i entusiasmo llenos
A la patria querida
Le diste libertad i nueva vida,
Colmaos de placer; las artes bellas,
Estas hijas laureadas de la gloria,
Viene a nos, i buscan en la Historia
Vuestras preciosas huellas
Para ilustrar vuestra inmortal memoria

Al relatar el cuadro de historia de Jacinto Chacón en su horizonte de expectativa para la recepción de su alocución, éste contiene indicaciones de lectura con la historia reciente del país. El presidente Manuel Bulnes, que se encuentra presente en la inauguración de la Academia, es representativo de los gobiernos conservadores, a quien le correspondió participar en batallas y guerras. Ahora

\footnotetext{
${ }^{13}$ Chacón, Jacinto, Seguido de la contestación en verso. Leída por D. Jacinto Chacón, página 24.
} 
en el lustro de su gobierno se asientan las bases del régimen republicano con la creación de instituciones educativas. De ahí el papel que le asigna el poeta a las artes bellas... para ilustrar vuestra inmortal memoria. Al igual que Cicarelli, Chacón reitera la función del arte de ilustrar los momentos de la historia del país, para que sus imágenes sirvan a la educación y memoria.

Si bien se vive un momento de pacificación no está ausente de tensiones como acciones que involucran a integrantes del Movimiento Literario de 1842 (nos referimos a la publicación de Francisco Bilbao por esos días), movimiento del cual forma parte Chacón como otros jóvenes de la aristocracia criolla que se identifican más con las ideas liberales, quienes, al igual que José Victorino Lastarria, piensan en el papel de la literatura como expresión de la sociedad y su aporte en la difusión de las luces.

La alocución de Chacón, en la intertextualidad con el discurso de Cicarelli, realiza una recontextualización de los referentes, resinificándolos desde una lectura local, en la que establece una especie de geopolítica. La venida de las musas al suelo americano son confrontadas en el paralelismo de Europa, el viejo mundo, y América, el nuevo mundo, y sus connotaciones aluden a Europa como el momento de vejez y declinación, en tanto en América todo rejuvenece, es un infante en formación.

Bien creo pues que se realice un día

Tú bella profesia.

Los grandes pensadores,

Profetas de la ciencia exploradores.

Gibbon, Quinet i Polo, Humboldt i Mora ${ }^{14}$

En el fragmento del poema citado, Chacón documenta su enciclopedia de lectura, que amplía en el pie de página de los saberes que circulan sobre el conocimiento de América, que se puede considerar como la arqueología de su saber. Ésta funciona como un paratexto que intertextualmente arma un campo de remisiones. Por cierto los autores mencionados son parte del programa de lecturas de los integrantes del Movimiento Literario de 1842 y de sus discusiones

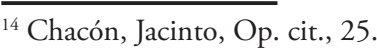


periódicas, tal es el caso que en una sesión del 30 de abril de 1843 se trata el método que debería adaptarse para el estudio de la historia.

A diferencia que la Academia que se encuentra en sus inicios, el sistema literario posee una institucionalidad y tradición que se refleja en las discusiones. Paralelamente en ese momento están problematizando sobre modelos y su imitación en relación con la producción cultural de Chile y su vinculación con América y el modo de recepción de la información proveniente de Europa. Por el contrario, la Academia recién comienza y durante veinte años el modelo de enseñanza será el transmitido por Ciccarelli, quien se inspira en el canon neoclásico. En el caso de la literatura, si bien con el característico descalce de la época, está la discusión de la implementación del modelo del Romanticismo.

Luego de su recorrido por imágenes de la historia, Chacón vuelve sobre la figura del pintor que llega y, coincidentemente se hace cómplice de la profecía de Ciccareli, la de Chile como la Atenas de América.

Si, gran pintor, lo espero

Chile tendrá su Zéuxis i su Homero

Musa Napolitana

Despierte, pues i la Musa Americana

Prepara tus pinceles

De nuestra Atenas, o modernos Apeles

Derrama el sacro fuego

¡Crea aquí Canovas i Rafaeles!

Que ya la noble juventud chilena,

Que ansiosa aguarda el porvenir Griego... ${ }^{15}$

El cuadro de la alocución de Chacón cierra su relato con el elogio a la figura del presidente Bulnes, en su rol edificante del porvenir de Chile y de la misión del Estado en el desarrollo cultural. En todo caso, Chacón especifica su ruda independencia en atención a su condición de Liberal.

${ }^{15}$ Ibíd. 


\section{APOSTILLA}

A modo de apostilla volvemos sobre la nota de pie de página que se puede considerar como un sistema de remisiones de lectura. En ella se establecen tres regímenes textuales. Primero, el analizado en la alocución, segundo la cita que funciona como una enciclopedia de lectura de la cual algunos de los autores y formadores son leídos por los representantes de Movimiento Literario de 1842. Esto permite relevar uno de los tópicos de discusión de la época sobre los modos de escribir la historia. (Es curioso lo resuelto a comienzos de 1843. El 30 de abril se trata sobre el método que debía adoptarse para el estudio de la historia. Este asunto se resolvió el 4 de abril. Después de alguna discusión, se determinó:

\footnotetext{
"Que todos los viernes hubiera lectura de historia, haciendo la de los pueblos antiguos, por Segre; la de la historia griega y romana por Golsmith; la de la Edad Media y Moderna por Fleury; y la de América por Robertson; y principiando el Herder luego que parezca conveniente. Aquí aparece una indicación del auge que tuvo el filósofo de la historia el alemán Herder, cuya influencia en Lastarria y en Sarmiento...)”. ${ }^{16}$
}

Y tercero, en la intertextualidad de la referencia el texto de Chacón, al interior de la cita que señala parte de la epístola que escribe en 1845 al historiador francés Edgar Quinet, del cual circula en la época la traducción de Johnn Gottfried Herder Filosofía de la historia, libro que sirve de antecedente en el debate sobre los modos de escribir la historia. Llama la atención para el periodo en análisis la sincronía en los tópicos en discusión y su interlocución, como se documentará a continuación:

"En otra remisión el cuadro de ideas de Chacón se triangula en el debate de 1848 sostenido a propósito del ensayo que José Victorino Lastarria presenta en 1847 al concurso de la Facultad de Filosofía y Humanidades de la Universidad de Chile: Bosquejo histórico de la constitución del gobierno de Chile, durante el primer periodo de la revolución desde 1810 hasta 1814. El prólogo es realizado por Chacón. Lo que Lastarria se planteó en esa oportunidad fue realizar un interesante trabajo de historia de las ideas politicas que rigieron la creación de los primeros gobiernos del Chile independiente, lo que no se habia hecho hasta el momento". ${ }^{17}$

\footnotetext{
${ }^{16}$ Latcham, Ricardo A. "Las ideas del movimiento literario de 1842", Revista Atenea XIX/LXVIII, No 28, Concepción (1942): 180 .

${ }^{17}$ Dager Alva, Joseph. "El debate en torno al método historiográfico en Chile del siglo XIX", Revista Complutense de Historia de América 28 (2002): 99.
} 
El contexto de la cita es en torno al debate historiográfico en el Chile de mediados del siglo XIX en el que se dan dos modelos: la historia narrativa o ad narrandum practicada por Andrés Bello y la historia ad probadum o historia filosófica representada por Lastarria y Chacón, que en el cuadro en análisis suscitó un debate iniciado por Bello a partir del prólogo de Chacón del ensayo antes mencionado de Lastarria.

Sumariamente el fondo de la discusión son dos distintas perspectivas sobre la reconstrucción del pasado en la naciente historiografía de América en el marco de la construcción de los Estados nacionales. La primera pondrá el acento en la documentación, en tanto la segunda en la valoración. Bello está en desacuerdo con la última por considerar lo naciente de los estados americanos y su estudio del pasado. Por el contrario, Lastarria y Chacón se adscriben a las "ideas sobre la filosofía de la historia del filósofo alemán (Herder) en la traducción de Edgar Quinet. Los miembros de la generación de 1842 leyeron a Herder y a Gusin con fruición y juvenil entusiasmo y creyeron ver en los postulados de la historia el cambio social”. ${ }^{18}$

Lo anterior se inscribe en lo que se ha designado como la polémica historiográfica de 1848, aspecto que ha sido estudiado con detención en el campo de la disciplina de la historia por Joseph Dager Alvar, entre otros. Bello responde el 7 de enero de 1848 en El Araucano, luego Chacón en El progreso el 25 de enero con Cuestión sobre la ciencia histórica. Nuevamente, Bello replica el 28 de enero Modo de escribir la historia, en el cual expone el método narrativo, estableciéndolo como canon de la época.

\section{CONCLUSIÓN}

La relación arte y literatura a mediados del siglo XIX en Chile, según los documentos analizados, se da con un desfase de siete años dada su institucionalidad y tradiciones, lo que pone en evidencia que en el sistema cultural de la época existen distintos desarrollos. Si en el subsistema literario de 1848 en la frontera con la historia se daba el debate historiográfico sobre los modos de escribir la historia, en las Bellas Artes recién en 1849 se inauguraba la Academia de Pintura.

\footnotetext{
${ }^{18}$ Pager Alva, Joseph, Op. cit., 103.
} 
Siguiendo el tópico del período, Chile país de historiadores, Miguel Luis Amunátegui publica en abril de 1849 el artículo Apuntes sobre lo que han sido las bellas artes en Chile, en la Revista de Santiago, crónica en la que el autor documenta la corta tradición de las bellas artes en Chile en la que cita como antecedencia el libro de Juan Ignacio Molina, Ensayo sobre la historia civil de Chile de 1787, donde relata el papel de los Jesuitas en las primeras manifestaciones artísticas de objetos para el culto. Con posteridad Amunátegui se ocupará de temas y biografías de carácter histórico. Otra de las fuentes que cita Amunátegui es la de José Gandarillas, relacionado con diferentes actividades vinculadas a la Bellas Artes en el siglo XIX. Ex alumno de Monvoisin, integrante del proyecto de la cofradía del Santo Sepulcro, es además a quien "el gobierno le había entregado 1000 pesos para los gastos que significarían la implementación de la sala", ${ }^{19}$ que refiere a la sala de pinturas, que sería el antecedente del museo según decreto de 1848.

Luego en sus apuntes, Amunátegui desarrolla un modelo discursivo semejante al de Cicarelli para dar cuenta de la historia del arte del país. Partiendo por la arquitectura, es decir, la herencia española, más adelante indica:

"veamos ahora que en cultura i pintura, cuya existencia no data por cierto mui atrás, según lo demuestran las siguientes palabras de Molina en su Historia escrita poco mas o menos en 1787 'Las Bellas Artes se encuentran en Chile dice, en un estado mui miserable. Las mecánicas también están ahora mui lejos de la perfección. Se debe exceptuar sin embargo las de carpintero, de herrero i platero i de platero, las cuales han hecho algún progreso a merced de las buenas luces que comunicaron algunos artesanos alemanes, que pasaron allí conducidos por el Padre Carlos, de los condes de Flainhausen, en Babiera, que quiso emplearse en aquella misión. Este benemérito relijioso que murió en $1766^{\prime \prime}{ }^{20}$

A partir de los apuntes de Amunátegui se utiliza como uno de los criterios para reconstruir la historia del arte chileno, el establecimiento como su inicio en el periodo colonial con el aporte de los Jesuitas y la pintura que llegaba desde de Quito.

\footnotetext{
${ }^{19}$ Amunátegui, Miguel Luis. "Apuntes sobre lo que han sido las Bellas Artes en Chile", Revista de Santiago. Tomo III. Santiago de Chile (1849): 44.

${ }^{20}$ Amunátegui, Miguel Luis, Op. cit., 47.
} 
"Tal ha sido i es, la facilidad i la disposición injénita de los naturales de Quito para la pintura, que borronean un cuadro casi sin aprender a manejar el pincel; más no teniendo reglas que los guien, no hacen más que mamarrachos, pero mamarrachos de resaltantes colores, que agradan en extremo a ignorantes colonos, a muchos de los cuales disgustaba el efectos de sombras en el rostro de las figuras, calificándolas de imágenes de cara sucia. Agregad el que eran mui barato i no costará mucho concebir cómo esa multitud de obras quiteñas cubrio paredes, de los claustros i de los salones". ${ }^{21}$

La valoración de Amunátegui sobre la producción quiteña es que no ha contribuido a la formación del gusto. También en sus juicios se deja entrever una de los problemas que se reiterará a futuro: el tema de los modelos y el original, lo que se traduce en la dependencia de lo extranjero.

El resto de las observaciones de los apuntes de Amunátegui, resumen un cuadro sobre las condiciones para el desarrollo de las Bellas Artes, que leídas en asociación con lo antes analizado y en especial con el discurso de Cicarelli, son una fuente de documentación para análisis posteriores. Por ejemplo Luis Álvarez Urquieta, los retomará en su libro La pintura en Chile. Colección Luis Álvarez Urquieta, que corresponde al catálogo del estudio de su colección, en el cual introduce otra fuente para el desarrollo de la pintura el sistema de arte chileno como indica en el índice: Capitulo I La prehistoria del arte. La cultura Atacameña-Arte Incaico y Araucano-Alguna reliquia histórica. ${ }^{22}$ Tal como indica en su introducción Onofre Jarpa, "Desde ahora para conocer toda la historia y toda la evolución del arte chileno, no es sólo al Museo de Bellas Artes que habrá que acudir, sino a la galería Álvarez Urquieta que merecería ser nacionalizada en el interés nacional y pública”. ${ }^{23}$ El libro fue publicado en 1928 y cuando el museo organiza una exposición de arte chileno en 1930 utiliza dicha colección, la que posteriormente es adquirida por la institución museal, y que también en la actualidad da inicio al relato de la colección del Museo Nacional de Bellas Artes.

Al cierre, lectura reversiva que pone de manifiesto la necesidad de revisión de fuentes primarias para la reconstrucción de la historiografía del arte chileno. En este caso, primer avance de la relación del arte y la literatura como fuente

\footnotetext{
${ }^{21}$ Amunátegui, José Miguel, Op. cit, 47.

${ }^{22}$ Álvarez Urquieta, Luis. La pintura en Chile. Colección Álvarez Urquieta, Santiago de Chile: Imprenta La ilustración, (1928): 12.

${ }^{23}$ Álvarez Urquieta, Luis Op. cit., 6.
} 
documental a partir de uno de los momentos fundacionales de las Bellas Artes en la lectura intertextual de los discursos de Cicarelli y Chacón en la inauguración de la Academia de Pintura.

\section{REFERENCIAS}

Álvarez Urquieta, Luis. La pintura en Chile. Colección Luis Álvarez Urquieta. Santiago de Chile: Imprenta La ilustración, 1928.

Amunátegui, Miguel Luis. "Apuntes sobre lo que han sido las Bellas Artes en Chile", Revista de Santiago. Tomo III. Santiago de Chile, 1849.

Berrios, Pablo et al. Del taller a las aulas. La institución moderna de Arte en Chile (1797-1910). Santiago de Chile: Estudios de Arte Santiago, 2009.

Cicarelli, Alejandro. Discurso pronunciado en la inauguración de la Academia de Pintura. Santiago de Chile: Imprenta chilena, 1849.

Chacón, Jacinto. Contestación leída en verso. Santiago de Chile: Imprenta chilena, 1849.

Dager Alva, Joseph. "El debate en torno al método historiográfico en Chile del siglo XX", Revista Complutense de Historia de América 28 (2002): 97-138.

Goic, Cedomil. La novela chilena. Los mitos degradados. 4a edición. Santiago de Chile: Editorial Universitaria, 1976.

Latcham, Ricardo A. "Las ideas del movimiento de 1842", Revista Atenea XIX/ LXVIII, N 28, Concepción, 1942.

Montes, Hugo y Orlando, Julio. Historia de la literatura chilena. Revisada y puesta al día. 10a edición. Santiago de Chile: Zig-Zag, 1982. 